\title{
Effectiveness of home exercise on pain and disability from osteoarthritis of the knee: a randomised controlled trial
}

\author{
Sheila C O’Reilly, Ken R Muir, Michael Doherty
}

\begin{abstract}
Objective-To assess the effect of a home based exercise programme, designed to improve quadriceps strength, on knee pain and disability.

Methods-191 men and women with knee pain aged 40-80 were recruited from the community and randomised to exercise $(n=113)$ or no intervention $(n=78)$. The exercise group performed strengthening exercises daily for six months. The primary outcome measure was change in knee pain (Western Ontario McMaster Osteoarthritis index (WOMAC)). Secondary measures included visual analogue scales (VAS) for pain on stairs and walking and WOMAC physical function scores.

Results-WOMAC pain score reduced by $22.5 \%$ in the exercise group and by $6.2 \%$ in the control group (between group difference $\mathrm{p}<0.05$, unpaired $t$ test).VAS scores for pain also reduced in the exercise group compared with the control group $(p<0.05)$. Physical function scores reduced by $17.4 \%$ in the exercise group and were unchanged in controls $(\mathbf{p}<0.05)$.

Conclusion-A simple programme of home quadriceps exercises can significantly improve self reported knee pain and function.

(Ann Rheum Dis 1999;58:15-19)
\end{abstract}

Knee osteoarthritis (OA) is common and contributes greatly to morbidity in the community. ${ }^{12}$ Treatment is generally aimed at reducing pain and maintaining function. There is increasing interest in the role of various forms of exercise therapy in $\mathrm{OA} .^{3}$ Exercises designed to strengthen the quadriceps muscles are often advocated yet evidence for their effectiveness is lacking. Many of the studies to date are limited by small numbers and lack of controls. ${ }^{4-6}$ In addition they have generally used sophisticated and expensive apparatus, which limits their application to a community setting. As hospital based, such studies have focused on subjects with moderate or severe structural change, in whom there may be limited scope for improvement.

The aim of this study was to assess the effect of a home based exercise programme, designed to improve quadriceps strength, on knee pain and disability.

Correspondence to: Dr S O'Reilly, Rheumatology Unit, City Hospital, Hucknall Road, Nottingham, NG5 1PB.

Accepted for publication 12 October 1998

Methods

SUBJECTS

Subjects were registered at two general practices in Nottingham. All had responded to a postal survey concerned with knee pain, details of which have been published elsewhere. ${ }^{7}$ Subjects had knee pain defined by an affirmative response to both parts of the following question "Have you ever had pain in or around the knee on most days for at least a month? If so, have you experienced any pain during the last year?" Subjects with knee pain were then contacted by telephone in random order as part of a case-control study, details of which have been published previously. ${ }^{8}$ Current knee pain was ascertained at this stage by the following question "Have you had any pain in your knees during the last week?" Subjects who answered "yes" were then invited to attend their local surgery for further assessment. Telephoning was continued until 300 subjects with knee pain had been recruited. This number was chosen to allow for those unwilling or ineligible to participate in the intervention study, in addition to satisfying requirements for the case-control study. ${ }^{8}$ From power calculations based on the primary outcome variable (predicted mean baseline pain score 6.3, SD 3.0 ), assuming a $20 \%$ reduction in score and a power of $80 \%$, a final study population of 175 was required. The following list of exclusions was applied at the time of the baseline assessment and before randomisation to exercise or control groups: already performing quadriceps exercises, clinical inflammatory arthropathy, pain referred from back or hip, serious injury within six months, previous knee replacement, unable to complete study because of imminent move or hospitalisation, no pain on WOMAC pain score, medical condition preventing exercise. Subjects who agreed to participate were randomised to exercise or to no intervention in a 3:2 ratio. Block randomisation was performed using random number tables and sealed envelopes. Four groups of randomisation were made: men aged 40-59, men aged 60-79, women aged 40-59, women aged 60-79. Subjects were asked to avoid starting new analgesics during the study period.

\section{ASSESSMENTS}

Assessments were performed at baseline and at six months (second assessment). Pain was assessed by the following measures:

1 Self reported total WOMAC pain score $^{9}$ (0-20, with higher scores indicating more pain) - primary outcome variable
2 Self reported visual analogue score (VAS) for walking on the flat $(0-100 \mathrm{~mm})$

3 Self reported VAS for pain while ascending/ descending stairs $(0-100 \mathrm{~mm})$ 


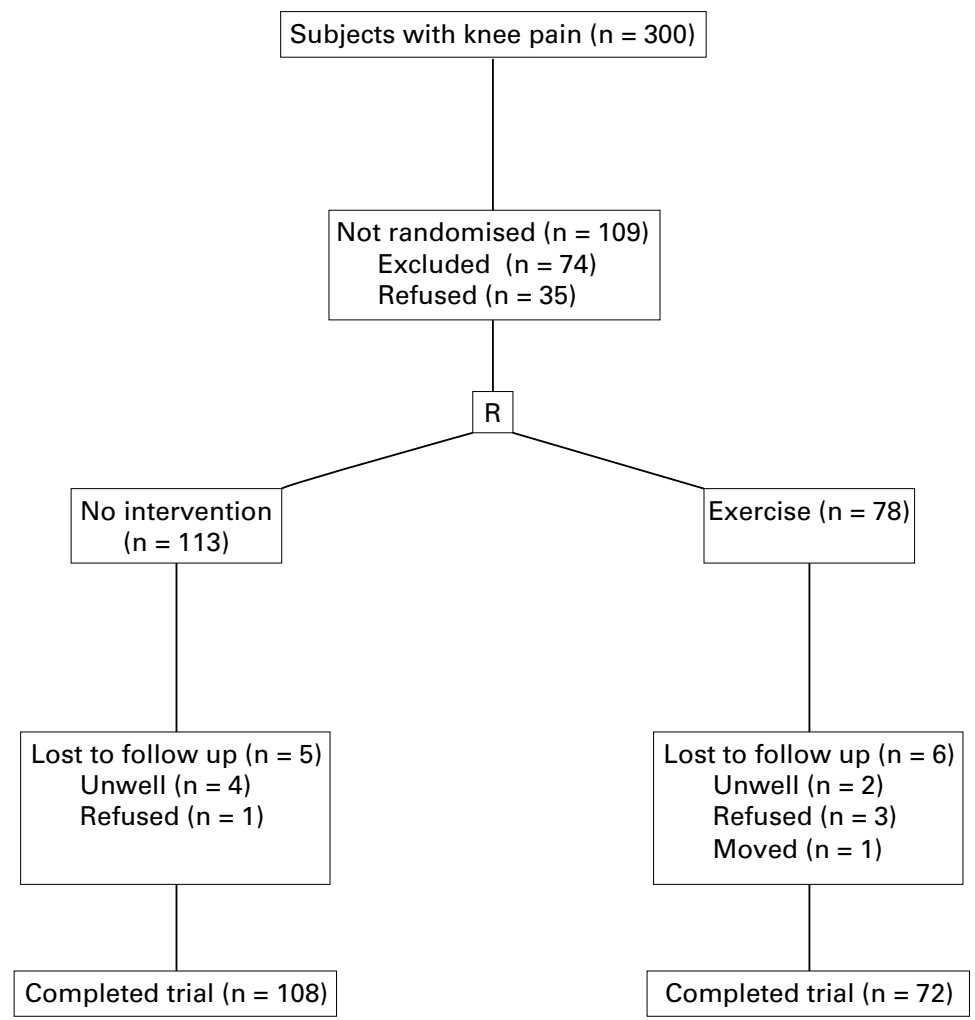

Figure 1 Summary data for study recruitment and completion.

The following secondary outcome measures were included:

1 Self reported WOMAC physical function score (0-68, with higher scores indicating more disability)

2 Isometric quadriceps strength measured by a single observer using a modified Tornvall chair $^{10}$

3 Quadriceps activation, measured by a single observer using twitch superimposition ${ }^{11}$

4 Self reported health status using the Anglicised version of the SF-36 health status questionnaire $^{12}(0-100$ for each dimension with higher scores indicating "better health")

5 Self reported anxiety and depression, using the Hospital Anxiety and Depression scale ${ }^{13}$ (scored 0-21, with higher scores indicating tendency to anxiety and depression)

6 Weight $(\mathrm{kg})$ measured by a single observer

7 Self reported analgesic usage per day

The initial assessment was carried out before randomisation into the study. It was not possible for the observer to be blinded to interven-

Table 1 Baseline data (means and standard deviations) on subjects completing the study

\begin{tabular}{|c|c|c|c|c|}
\hline & \multicolumn{2}{|c|}{ Exercise group $(n=108)$} & \multicolumn{2}{|c|}{ Control group $(n=72)$} \\
\hline & Mean & $S D$ & Mean & $S D$ \\
\hline Age & 61.94 & 10.01 & 62.15 & 9.73 \\
\hline Weight $(\mathrm{kg})$ & 76.61 & 24.23 & 75.79 & 16.90 \\
\hline WOMAC pain score & 6.45 & 3.50 & 6.75 & 2.83 \\
\hline WOMAC function score & 20.38 & 12.54 & 19.51 & 11.52 \\
\hline Anxiety score (HAD) & 7.06 & 3.69 & 6.82 & 3.65 \\
\hline Depression score (HAD) & 4.58 & 2.91 & 4.79 & 2.91 \\
\hline Right quads strength ( $\mathrm{kgF})$ & 23.61 & 11.80 & 22.85 & 11.99 \\
\hline Left quads strength $(\mathrm{kgF})$ & 22.23 & 11.13 & 22.90 & 10.78 \\
\hline Right activation (\%) & 79.60 & 25.53 & 76.48 & 26.11 \\
\hline Left activation $(\%)$ & 77.04 & 25.83 & 81.39 & 24.17 \\
\hline
\end{tabular}

tion group at the second assessment. In addition to the above assessments, subjects were asked to state at the end of the study whether their knees were; much better, slightly better, the same, slightly worse or much worse. All subjects had radiograph of the knees (AP weight bearing and skyline) obtained after the first assessment. These were graded for maximum osteophyte grade in either compartment (patellofemoral or tibiofemoral) using a standard atlas. ${ }^{14}$ All assessments, with the exception of radiographs, were carried out at the local surgeries. Written consent was obtained for the initial assessment. After randomisation, consent was obtained for the intervention (exercise group only) and second assessment (both groups).

\section{INTERVENTION}

General advice

A simple verbal explanation concerning knee pain and knee OA was given to all study subjects before randomisation. In addition all subjects were advised on the importance of losing weight or not becoming overweight, wearing training shoes/air filled soles and maintaining fitness by walking or swimming.

\section{Exercise group}

A graded exercise programme was devised. Five exercises were included:

1 Isometric quadriceps contraction in full extension held for five seconds (subject sits on floor with back supported and legs extended, with rolled up towel under one knee and contracts quadriceps by pushing into the floor against towel)

2 Isotonic quadriceps contraction held in mid flexion for five seconds (subject sits in a chair, lifts lower leg to partially extended position and holds)

3 Isotonic hamstring contraction (subjects lies on front or side and bends knee bringing foot towards body)

4 Isotonic quadriceps contraction with resistance band held for five seconds (as for exercise 2)

5 Dynamic stepping exercise (walking up and down one step/stair)

Exercises were started in the above order and increased to a maximum of 20 repetitions on each leg. Exercises were performed at home on a daily basis, having been taught by a nurse metrologist. In addition to the initial visit, subjects were visited on three further occasions (at two weeks, six weeks, and three months) by the metrologist.

\section{Control group}

Subjects in the control group did not receive specific intervention and were not visited between assessments.

\section{COMPLIANCE}

Subjects were asked to complete a diary documenting the number of exercises performed each day. Compliance was graded into four categories based on the number of exercises performed over the study period. 
Table 2 Mean change (with 95\% confidence intervals) in global WOMAC pain scores, visual analogue scores for pain on walking and stairs and global WOMAC physical function scores; with corresponding between group differences and $95 \%$ confidence intervals ( ${ }^{\star} p$ between group difference, unpaired $t$ test)

\begin{tabular}{|c|c|c|c|c|c|c|c|c|c|}
\hline & \multicolumn{3}{|c|}{ Exercise group } & \multicolumn{6}{|c|}{ Control group } \\
\hline & $\begin{array}{l}\text { Mean } \\
\text { change }\end{array}$ & $95 \% C I$ & $\%$ change & $\begin{array}{l}\text { Mean } \\
\text { change }\end{array}$ & $95 \% C I$ & $\%$ change & $\begin{array}{l}\text { Mean } \\
\text { difference }\end{array}$ & $95 \% C I$ & ${ }^{*} p$ Value \\
\hline Global pain score & -1.45 & $-2.04,-0.86$ & -22.5 & 0.42 & $-1.09,0.25$ & -6.2 & -1.04 & $-1.94,-0.14$ & 0.02 \\
\hline VAS walking & -6.64 & $-10.97,-2.31$ & -20.9 & 0.43 & $-3.88,4.74$ & 1.5 & -7.07 & $-13.40,-0.74$ & 0.03 \\
\hline VAS stairs & -9.08 & $-15.33,-2.84$ & -18.6 & 1.34 & $-3.90,6.60$ & 3.0 & -10.43 & $-19.15,-1.71$ & 0.02 \\
\hline Physical function score & -3.55 & $-5.34,-1.75$ & -17.4 & -0.01 & $-1.75,1.72$ & 0.1 & -3.53 & $-6.13,-0.93$ & 0.01 \\
\hline
\end{tabular}

STATISTICAL ANALYSIS

Data were analysed on an intention to treat basis, irrespective of the degree of compliance with the exercise programme. Differences from baseline were calculated for all primary and secondary outcome variables. Mean differences and 95\% confidence intervals (CI) were calculated for all outcome measures. Between group differences were compared using unpaired $t$ tests. Statistical testing for secondary outcome measures was restricted to function and muscle strength. All analyses were performed using SPSS for Windows 6.0 (SPSS Inc).

\section{Results}

SUBJECTS

The response rate to the postal survey was $81.9 \%$ with $28.7 \%$ of subjects reporting knee pain. ${ }^{7}$ Four hundred and seventy four of these subjects were telephoned, of whom 131 were pain free at the time of the telephone contact and 43 were unwilling to participate. Of the 300 subjects with knee pain who attended the baseline assessment, 191 subjects were recruited into the intervention study, of which 113 were randomised to the exercise group and 78 to the control group (fig 1 ). Of the 109 subjects not recruited, 35 were unwilling to participate and 74 were excluded (already performing quadriceps exercises $n=24$, clinical inflammatory arthropathy $n=12$, pain referred from back or hip $n=12$, serious injury in last six months $n=7$, previous knee replacement $n=5$, unable to complete study because of imminent move or hospitalisation $n=5$, pain free (WOMAC score $=0$ ) at first assessment $n=4$, medical condition preventing exercise $n=5$. One hundred and eighty subjects (94.2\%) attended for reassessment; 108 exercisers and 72 controls. The proportion of men and women in each group was similar (exercise group $64.8 \%$ women, control group $68.1 \%$ women). Table 1 shows other baseline characteristics. Mean values were similar for all data with the exception of activation where standard deviations were wide. Radiographs were obtained on 161 subjects $(89.4 \%)$ who completed the study. Frequency of subjects with $\geqslant$ grade 1 osteophyte (in either knee in any compartment) was high in both groups $(75.3 \%$ in exercise group, $78.1 \%$ in control group). Osteophyte ( $\geqslant$ grade 1 ) was more common in the patellofemoral compartment $(73.9 \%$ of subjects) than in the tibiofemoral compartment (52.8\% of subjects). Grade 2 osteophyte or above was less common, occurring in 66 subjects $(40.9 \%)$. Analgesic usage was similar in the two groups. Values were obtained for all outcome variables for each subject and hence the results presented relate to the 108 subjects in the exercise group and 72 subjects in the control groups.

PAIN

Table 2 shows the differences in WOMAC pain scores. Pain scores were reduced by $22.5 \%$ in the exercise group and by $6.2 \%$ in the control group. The between group difference was statistically significant $(p<0.05)$. VAS assessments for pain (walking on the flat and negotiating stairs) showed a similar trend (table 2 ).

\section{PHYSICAL FUNCTION}

Table 2 shows the results for physical function. WOMAC score was reduced by $17.4 \%$ in the exercise group and was unchanged in the control group; the between group difference being statistically significant $(\mathrm{p}<0.05)$.

\section{QUADRICEPS STRENGTH AND ACTIVATION}

Table 3 shows the differences for right and left isometric quadriceps voluntary strength. Gains in strength were demonstrated in the exercise group with reductions in the control group. Corresponding figures for quadriceps activation were more variable (table 3), but suggested small increases in the exercise group.

\section{HEALTH STATUS}

Table 4 shows the results for SF-36 health status dimensions. A trend towards improvements

Table 3 Mean change (with 95\% confidence intervals) in voluntary quadriceps strength and quadriceps activation; with corresponding between group differences and $95 \%$ confidence intervals ( ${ }^{*}$ p between group difference, unpaired t test)

\begin{tabular}{|c|c|c|c|c|c|c|c|c|c|}
\hline & \multicolumn{3}{|c|}{ Exercise group } & \multicolumn{6}{|c|}{ Control group } \\
\hline & $\begin{array}{l}\text { Mean } \\
\text { change }\end{array}$ & $95 \% C I$ & $\%$ change & $\begin{array}{l}\text { Mean } \\
\text { change }\end{array}$ & $95 \% C I$ & $\%$ change & $\begin{array}{l}\text { Mean } \\
\text { difference }\end{array}$ & $95 \% C I$ & ${ }^{*} p$ Value \\
\hline \multicolumn{10}{|l|}{ Right quadriceps } \\
\hline Quads strength (kgF) & 1.09 & $-0.21,2.40$ & 4.7 & -1.13 & $-2.54,0.25$ & -4.9 & 2.24 & $0.29,4.19$ & 0.03 \\
\hline Activation $(\%)$ & 4.50 & $0.00,9.00$ & 5.7 & 2.32 & $-3.99,8.62$ & 3.0 & 2.18 & $-5.32,9.68$ & 0.6 \\
\hline \multicolumn{10}{|l|}{ Left quadriceps } \\
\hline Quads strength $(\mathrm{kgF})$ & 0.88 & $-0.37,2.12$ & 4.0 & -1.63 & $-3.15,-0.10$ & -7.1 & 2.51 & $0.55,4.46$ & 0.01 \\
\hline Activation (\%) & 4.96 & $0.71,9.21$ & 6.4 & -5.90 & $-12.07,0.27$ & -7.2 & 10.96 & $3.67,18.05$ & 0.01 \\
\hline
\end{tabular}


Table 4 Mean change (with 95\% confidence intervals) in SF-36 health status dimensions

\begin{tabular}{|c|c|c|c|c|c|c|}
\hline & \multicolumn{3}{|c|}{ Exercise group } & \multicolumn{3}{|c|}{ Control group } \\
\hline & $\begin{array}{l}\text { Mean } \\
\text { change }\end{array}$ & $95 \% C I$ & $\%$ change & $\begin{array}{l}\text { Mean } \\
\text { change }\end{array}$ & $95 \% C I$ & $\%$ change \\
\hline Physical function & 2.68 & $-0.38,5.73$ & 4.7 & -1.63 & $-5.23,1.96$ & -3.1 \\
\hline Mental health & -0.21 & $-2.77,2.34$ & -0.3 & -2.91 & $-6.62,0.79$ & -3.9 \\
\hline Energy & 2.47 & $-0.62,5.56$ & 4.6 & 0.56 & $-3.91,5.04$ & 1.2 \\
\hline Bodily pain & 4.97 & $0.64,9.30$ & 9.0 & 0.16 & $-5.47,5.80$ & 0.3 \\
\hline Health perception & 1.93 & $-0.75,4.61$ & 3.3 & -0.70 & $-3.91,2.50$ & -1.3 \\
\hline Role limitation physical & 3.19 & $-3.83,10.21$ & 6.3 & -7.59 & $-16.47,1.30$ & -17.5 \\
\hline Role limitation emotional & 1.85 & $-6.66,10.36$ & 2.7 & 0.48 & $-13.35,14.32$ & 0.7 \\
\hline Social functioning & 1.89 & $-2.87,6.64$ & 2.4 & 1.90 & $-7.22,11.03$ & 2.8 \\
\hline
\end{tabular}

in health in the exercise group was apparent though confidence intervals were wide.

\section{OTHER FACTORS}

The exercise group demonstrated improvements in terms of anxiety and depression with either no change or deterioration in the control group (table 5). A similar trend was apparent for weight. Analgesic usage decreased slightly in the exercise group and was unchanged in the control group.

\section{COMPLIANCE}

Table 6 shows the differences in pain and strength in terms of compliance with exercise. With the exception of total pain score, improvements were most marked in the most compliant subjects.

\section{Discussion}

A reduction in pain has been shown with a home exercise programme, which is consistent for all measures of pain. Pain has not been the primary outcome measure in previous studies and has been omitted completely in some. ${ }^{15}$ One study reported a $35 \%$ reduction in pain, ${ }^{6}$ while other studies have reported unquantified improvements. ${ }^{4}$ Varying methods of assessments make direct comparison difficult. Nevertheless, the larger effect in the Fisher study in comparison with this study is not surprising, given the intensity of the exercise programme and the degree of supervision. A similar reduction in pain to this study was documented in one of the few controlled studies. ${ }^{16}$ Although a secondary outcome measure, physical function is nevertheless important. The magnitude of

Table 5 Mean change (with 95\% confidence intervals) in anxiety and depression scores and in weight

\begin{tabular}{|c|c|c|c|c|c|c|}
\hline & \multicolumn{3}{|c|}{ Exercise group } & \multicolumn{3}{|c|}{ Control group } \\
\hline & $\begin{array}{l}\text { Mean } \\
\text { change }\end{array}$ & $95 \% C I$ & $\%$ change & $\begin{array}{l}\text { Mean } \\
\text { change }\end{array}$ & $95 \% C I$ & $\%$ change \\
\hline Anxiety score & -0.57 & $-1.14,0.00$ & -8.1 & 0.06 & $-0.66,0.77$ & 0.0 \\
\hline Depression score & -0.57 & $-0.96,-0.19$ & -12.4 & 0.11 & $-0.37,0.59$ & 2.2 \\
\hline Weight $(\mathrm{kg})$ & -3.22 & $-7.02,0.57$ & -4.2 & 1.40 & $-1.42,4.22$ & 1.8 \\
\hline
\end{tabular}

Table 6 Mean differences in pain and muscle strength in the exercise group by level of compliance

\begin{tabular}{lllll}
\hline \multicolumn{4}{l}{ Total exercise time missed } \\
\cline { 2 - 5 } & $<2$ weeks & $<6$ weeks & $<3$ months & $>3$ months \\
\hline Total pain score & -1.65 & -1.50 & 1.75 & -1.85 \\
VAS walking & -9.26 & -8.07 & 1.87 & -0.62 \\
VAS stairs & -15.05 & -12.07 & 6.63 & 2.48 \\
Right quadriceps strength & 2.36 & 1.85 & -2.09 & -1.90 \\
\hline
\end{tabular}

change is less than in reported hospital based trials, ${ }^{6}$ but is still significant. Similar results in terms of function have been reported from a large study of community derived subjects with knee OA. As with other studies, however, the exercise programme was hospital based and intensively supervised. ${ }^{17}$

It is not clear how much of this improvement in pain and function relates to change in muscle strength. The improvements in strength were modest. Fisher and colleagues reported increases in strength of $14-35 \% .{ }^{6}{ }^{18}$ Other studies have demonstrated improvements of $13-29 \% .^{15} 16$ It may be that the exercise programme in this study lacked intensity. As it was home based and required minimal supervision, it was designed with safety in mind. Alternatively, the difference may be because of differences in measurement. Several studies have exercised at the same muscle length used for measurement. ${ }^{15} 16$ As some degree of specificity exists, this will maximise measured increases in strength. ${ }^{19} \mathrm{~A}$ third possibility is compliance, particularly as this was a home programme. Drop out rate was small, however, and over $70 \%$ of subjects in the intervention group completed $75 \%$ of the programme, a figure that compares favourably with other studies of home exercise. ${ }^{2021}$ Only one previous study has reported change in muscle activation after rehabilitation in a similar population. ${ }^{22} \mathrm{~A}$ reduction of $15 \%$ was demonstrated but was achieved with an intensive, supervised exercise programme. The reduction in muscle strength in the control group is difficult to explain. As control subjects were advised of the benefit of exercise in general, it is unlikely that they reduced their levels of activity. Alternatively, as it was a voluntary measure, they may have been less motivated than the exercise group. The lack of blinding of the assessor may also have been implicated although efforts were made to encourage all subjects.

The possibility that improvements in pain and disability may, at least in part, relate to factors other than muscle strength, must be considered. With the exception of muscle strength, outcome measures were self assessed and may therefore, as with all exercise studies, be influenced by lack of subject blinding. It was also impossible for the assessor to be blinded to treatment group in this study. While, as mentioned, this could have influenced assessment of muscle strength, it is unlikely to have had a major effort on the other more important outcome measures. Reduction in levels of anxiety and depression were apparent in the 
exercise group. It is not clear whether this was a primary or secondary effect. Contact with a therapist may have had an effect on psychological outlook. Positive effects on pain and disability in OA have previously been reported with telephone contact. ${ }^{23}$ Alternatively, self perceived reduction in pain and disability may lead to improved mental health. Such an effect has been demonstrated previously following aerobic exercise. ${ }^{24}$

Reductions in weight are also apparent in the exercise group. Two small studies have demonstrated a positive effect on symptoms after weight reduction. ${ }^{25}{ }^{26}$ It is possible, however, that this represents a secondary effect because of improvements in physical activity. Analgesic usage is unlikely to account for improvements in pain. Baseline assessments were similar in the groups, and analgesic requirements tended to reduce in the exercise group.

The trend towards greater improvements in pain and function in the subjects most compliant with the exercise programme adds support for strength gain being the key factor. The improvement in WOMAC pain score in the least compliant group is, however, somewhat contradictory. It is possible that these subjects stopped exercising because of clinical improvement. While numbers are small, there is some evidence for this, with $35 \%$ of this group reporting improvement, compared with none in the next most compliant group.

Distinguishing between clinical and statistical significance is important in any clinical trial. Levels for statistical significance reached in the current study are borderline. This may in part relate to "placebo effect", as pain scores were reduced in the control group, an effect that is well recognised in osteoarthritis trials. As baseline measures were similar between groups it would have been possible to analyse within group differences. This would, however, have required additional comparisons with the inherent risk of type I errors. An alternative and perhaps more important influence in terms of statistical outcome is the dispersion of outcome values. Deviations and hence confidence intervals were wide in comparison with previously reported figures in hospital referred populations. As power calculation were based on a slightly lower standard deviation than measured, a power of $80 \%$ has not been achieved. Nevertheless for several reasons the result can be regarded as clinically significant. Subjects were highly heterogeneous in terms of age, muscle strength, severity of pain, and radiological change. Overall the population had less pain than in previous studies. In addition this was a simple low cost package of exercise with minimal supervision. A mean reduction in pain of $22 \%$ may, in this context, be considered to have clinical importance.

This study has focused on knee pain rather than structural change. Although most subjects did have evidence of osteophytosis, these results may not be generalisable to a population with severe radiographic OA. As pain is the most common reason for seeking medical intervention, however, these results are highly pertinent to the primary care setting.
The authors would like to thank the general practitioners, staff and patients of the Stenhouse Medical Centre and Calverton Surgery for their cooperation.

The authors are grateful to the Arthritis and Rheumatism Council for Research, UK for providing financial support.

1 Felson DT, Naimark A, Anderson JJ, Kazis L, Castelli W, Meenan RF. The prevalence of knee osteoarthritis in the elderly: the Framingham osteoarthritis study. Arthritis Rheum 1987;30:914-18.

2 Badley EM, Tennant A. Disablement associated with rheumatic disorders in a British population: problems with activities of daily living and level of support. Br J Rheumatol 1993;32:601-8.

3 Minor MA. Arthritis and exercise: the times they are a-changin'. Arthritis Care Res 1996;9:79-81.

4 Chamberlain MA, Care G, Harfield B. Physiotherapy in osteoarthrosis of the knees: a controlled trial of hospital versus home exercises. Int Rehab Med 1982;4:101-6.

5 Marks R. The effect of isometric quadriceps strength training in mid-range for osteoarthritis of the knee. Arthritis Care Res 1993;6:52-6.

6 Fisher NM, Prendergast DR, Gresham GE, Calkins E. Muscle rehabilitation: its effect on muscular and functional performance of patients with knee osteoarthritis. Arch Phys performance of patients with kn

7 O'Reilly SC, Muir KR, Doherty M. Screening for knee pain in osteoarthritis: which question? Ann Rheum Dis 1996;55:931-3.

8 O'Reilly SC, Jones A, Muir KR, Doherty M. Quadriceps weakness in knee osteoarthritis: the effect on pain and disability. Ann Rheum Dis 1998;57:588-94.

9 Bellamy N, Buchanan WW, Goldsmith $\mathrm{CH}$, Campbell J. Validation study of WOMAC: a health status instrument for measuring clinically-important patient-relevant outcomes following total hip or knee arthroplasty in osteoarthritis. J Orthop Rheumatol 1988;1:95-108.

10 Tornvall G. Assessment of physical capabilities with special reference to the evaluation of maximum voluntary isometric muscle strength. Acta Physiol Scand 1963;58 (suppl 201):1-102.

11 Rutherford OM, Jones DA, Newham DJ. Clinical and experimental application of the percutaneous twitch superimposition technique for the study of human muscle activation. J Neurol Neurosurg Psychiatry 1986;49:128891.

12 Brazier JE, Harper R, Jones NM, O'Cathain A, Thomas KJ, Usherwood T, et al. Validating the SF-36 health survey questionnaire: new outcome measure for primary care. BMJ 1992;305:160-5.

13 Zigmond AS, Snaith RP. The hospital anxiety and depression scale. Acta Psychiatr Scand 1983;67:361-70.

14 Burnett S, Hart DJ, Cooper C, Spector TD. A radiographic atlas of osteoarthritis. London: Springer Verlag, 1994.

15 Kreindler H, Lewis CB, Rush S, Schaefer K. Effects of three exercise protocols on the strength of persons with osteoarthritis of the knee. Top Geriatr Rehabil 1989;4:32-9.

16 Callaghan MJ, Oldham JA, Hunt J. An evaluation of exercise regimes for patients with osteoarthritis of the knee: a single-blind randomized controlled trial. Clin Rehabil 1995;9:213-17.

17 Ettinger WH, Burns R, Messier SP, Applegate W, Rejeski WR, Morgan T, et al. A randomized trial comparing aerobic exercise and resistance exercise with a health education program in older adults with knee osteoarthritis. JAMA program in older

18 Fisher NM, Gresham GE, Prendergast DR. Effects of a quantitative progressive rehabilitation program applied unilaterally to the osteoarthritic knee. Arch Phys Med Rehabil 1993;74:1319-26.

19 Lindh M. Increase of muscle strength from isometric quadriceps exercises at different knee angles. Scand J Rehab Med 1979;11:33-6.

20 Green J, McKenna F, Redfern EJ, Chamberlain MA. Home exercises are as effective as outpatient hydrotherapy for osteoarthritis of the knee. Br J Rheumatol 1993;32:812-15.

21 Fisher NM, Kame VD, Rouse L, Prendergast DR. Quantitative evaluation of a home exercise program on muscle and functional capacity of patients with osteoarthritis. Am J Phys Med Rehabil 1994;73:413-20.

22 Hurley MV, Newham DJ. The influence of arthrogenous muscle inhibition on quadriceps rehabilitation of patients with early, unilateral osteoarthritic knees. $\mathrm{Br} \mathrm{J}$ Rheumatol 1993;32:127-31.

23 Weinberger M, Tierny WM, Booher P, Katz BP. Can the provision of information to patients with osteoarthritis provision of information to patients with osteoarthritis
improve functional status. Arthritis Rheum 1989;32:1577imp.

24 Minor MA, Hewett JE, Webel RR, Anderson SK, Kay DR. Efficacy of physical conditioning exercise in patients with rheumatoid arthritis and osteoarthritis. Arthritis Rheum 1989;32:1396-405.

25 McGoey BV, Deitel M, Saplys RJ, Kliman ME. Effect of weight loss on musculoskeletal pain in the morbidly obese. J Bone Joint Surg Br 1990;72-B:322-3.

26 Loesser RF, Messier SP, Valle G, Morgan TM, Ettinger WH. The effect of an exercise and weight loss intervention on osteoarthritis of the knee. Arthritis Rheum 1995;38 (suppl):268 